\title{
Multinational evidence-based recommendations on how to investigate and follow-up undifferentiated peripheral inflammatory arthritis: integrating systematic literature research and expert opinion of a broad international panel of rheumatologists in the $3 \mathrm{E}$ Initiative
}

\author{
P Machado, ${ }^{1,2}$ I Castrejon, ${ }^{3}$ W Katchamart, ${ }^{4}$ R Koevoets, ${ }^{2}$ B Kuriya ${ }^{4,5}$ M Schoels, ${ }^{6}$ \\ L Silva-Fernández, ${ }^{7}$ K Thevissen, ${ }^{8}$ W Vercoutere, ${ }^{9}$ E Villeneuve, ${ }^{10} \mathrm{D}$ Aletaha, ${ }^{11}$ \\ L Carmona, ${ }^{12} \mathrm{R}$ Landewé, ${ }^{13}$ D van der Heijde, ${ }^{2} \mathrm{~J}$ W J Bijlsma, ${ }^{14}$ V Bykerk, ${ }^{4}$ H Canhão, ${ }^{15}$ \\ A I Catrina, ${ }^{16} \mathrm{P}$ Durez, ${ }^{17} \mathrm{C}$ J Edwards, ${ }^{18} \mathrm{M}$ D Mjaavatten, ${ }^{19}$ B F Leeb, ${ }^{20}$ B Losada, ${ }^{21}$ \\ E M Martín-Mola, ${ }^{22}$ P Martinez-Osuna, ${ }^{23}$ C Montecucco, ${ }^{24}$ U Müller-Ladner, ${ }^{25}$ \\ M Østergaard, ${ }^{26}$ B Sheane, ${ }^{27}$ R M Xavier, ${ }^{28} \mathrm{~J}$ Zochling, ${ }^{29} \mathrm{C}$ Bombardier ${ }^{30,31}$
}

For numbered affiliations see end of article

\section{Correspondence to Dr Pedro Machado, Department of Rheumatology, Coimbra University Hospital, Praceta Mota Pinto, 3000-075 Coimbra, Portugal; pedrommcmachado@gmail. com}

PM, IC, WK, RK, BK, MS, LS-F, $K T, W V$ and EV contributed equally to this work.

Accepted 10 July 2010 Published Online First 19 August 2010

\section{ABSTRACT}

Objective To develop evidence-based recommendations on how to investigate and follow-up undifferentiated peripheral inflammatory arthritis (UPIA).

Methods 697 rheumatologists from 17 countries participated in the $3 \mathrm{E}$ (Evidence, Expertise, Exchange) Initiative of 2008-9 consisting of three separate rounds of discussions and modified Delphi votes. In the first round 10 clinical questions were selected. A bibliographic team systematically searched Medline, Embase, the Cochrane Library and ACR/EULAR 2007-2008 meeting abstracts. Relevant articles were reviewed for quality assessment, data extraction and synthesis. In the second round each country elaborated a set of national recommendations. Finally, multinational recommendations were formulated and agreement among the participants and the potential impact on their clinical practice was assessed.

Results A total of 39756 references were identified, of which 250 were systematically reviewed. Ten multinational key recommendations about the investigation and follow-up of UPIA were formulated. One recommendation addressed differential diagnosis and investigations prior to establishing the operational diagnosis of UPIA, seven recommendations related to the diagnostic and prognostic value of clinical and laboratory assessments in established UPIA (history and physical examination, acute phase reactants, autoantibodies, radiographs, $\mathrm{MRI}$ and ultrasound, genetic markers and synovial biopsy), one recommendation highlighted predictors of persistence (chronicity) and the final recommendation addressed monitoring of clinical disease activity in UPIA.

Conclusions Ten recommendations on how to investigate and follow-up UPIA in the clinical setting were developed. They are evidence-based and supported by a large panel of rheumatologists, thus enhancing their validity and practical use.

\section{INTRODUCTION}

In clinical practice, a large number of patients who present with recent-onset arthritis have undifferentiated peripheral inflammatory arthritis (UPIA). In this context, patients' initial questions will focus on their likelihood of developing a well-defined rheumatic disease and on what the future holds for disease progression, persistence, functional impairment and quality of life. These are questions about future diagnosis and prognosis. The answers to these questions are vital for clinical decision making, including the choice of treatment.

The 3E Initiative (Evidence, Expertise, Exchange) in rheumatology is a multinational effort aimed at promoting evidence-based medicine by formulating practical recommendations addressing clinical problems. ${ }^{12}$ The objective of the $3 \mathrm{E}$ Initiative of 2008-9 was to develop practical recommendations on how to investigate and follow-up undifferentiated peripheral inflammatory arthritis by integrating systematically generated evidence and expert opinion of a broad panel of international rheumatologists. Although the term 'inflammatory' in UPIA may seem redundant, the reason for its use was to clearly distinguish the target population from patients with degenerative joint disease, often called osteoarthritis or degenerative arthritis in the English medical literature.

\section{METHODS}

A total of 697 rheumatologists from 17 countries participated in the 3E Initiative of 2008-9. Each country was represented by a scientific committee consisting of one principal investigator and 5-13 members. The bibliographic team consisted of 10 international fellows (PM, IC, WK, RK, BK, MS, LS-F, KT, WV, EV) and five mentors (DA, LC, $\mathrm{RL}, \mathrm{DvdH}, \mathrm{CB}$ ), one of the mentors also being the scientific organiser (CB). The 17 national principal investigators were selected and invited by the $3 \mathrm{E}$ scientific organiser (CB) and each national chair was in charge of composing a national steering committee. The experts were all the members of 
the 17 national steering committees who attended the multinational meetings for the $3 \mathrm{E}$ Initiative.

During the first international meeting ( $\mathrm{n}=113$ participants), 10 clinically relevant questions on how to investigate and follow-up UPIA were formulated and selected via a modified Delphi vote. The areas addressed were fourfold: (1) the phase prior to establishing the operational diagnosis of UPIA - namely, which differential diagnosis should be considered in a patient presenting with (inflammatory) arthritis and the minimal investigations necessary to consider a patient as having UPIA; (2) the diagnostic and prognostic value of clinical assessment and investigations in UPIA (history and physical examination, acute phase reactants, autoantibodies, x-rays, MRI, ultrasound (US), genetic markers and synovial biopsy); (3) the predictors of persistence (chronicity) in UPIA; and (4) the measures of clinical disease activity in UPIA.

The clinical questions were structured using the PIO format (Patients, Participants or Problem; Intervention or Index test; Outcomes or target conditions). ${ }^{3}$ The patients included 'adults with UPIA'. Duration of symptoms was not an exclusion criterion. The definition of UPIA is controversial and there is no widely accepted classification criterion for this condition. During the 2008-9 3E Initiative kick-off meeting, experts decided that only patients in whom clinically apparent joint swelling (synovial proliferation or synovial effusion) was observed by the rheumatologist should be included. For our review we systematically searched for studies of patients who did not fulfil diagnostic/classification criteria for any specific rheumatic disorder after initial assessment. Studies with mixed populations (eg, UPIA+arthralgia, UPIA+early rheumatoid arthritis (RA)) were also retained, as these could be useful for extrapolating results. The intervention or index test was defined according to each question (eg, erosions on $\mathrm{x}$-rays, anti-citrullinated protein/peptide antibodies (ACPA) positivity) and the index test should have been assessed at baseline. The outcomes were defined as the development of well-defined rheumatic diseases (eg, RA, psoriatic arthritis) or relevant disease outcomes (eg, remission, radiographic progression). As diagnostic/classification criteria we accepted either internationally validated criteria (eg, American College of Rheumatology criteria for $\mathrm{RA}^{4}$ ) or the opinion of the treating physician/investigator.

A systematic literature search for articles published up to February 2009 was carried out in Medline, Embase and Cochrane Library using comprehensive search strategies elaborated in collaboration with experienced librarians. The searches were limited to diagnostic and prognostic studies using a modification of published sensitive search strategies. ${ }^{5-8}$ No language restrictions were used. Retrieved citations were screened for titles, abstracts and full text using predefined inclusion and exclusion criteria; full read papers and review articles were hand-searched for additional references. Retained articles were graded for their methodological quality according to the levels of evidence of the Oxford Centre for Evidence-Based Medicine (http://www. cebm.net/index.aspx?o=1025).

Each question was addressed separately by independent searches. For each question, relevant data were extracted and appropriate statistics were calculated, including OR, sensitivity, specificity, positive/negative predictive values and positive/ negative likelihood ratios. Details and results of the literature search for each question will be published separately, while the current article describes the merging process between the evidence found for each question and the interpretation of this by the experts, having the 10 recommendations as the result.

In the second round, a national meeting was held in each country (total=697 participants) to discuss the generated evidence and propose a set of recommendations. In a third joint meeting the 17 scientific committees ( $\mathrm{n}=94$ participants) merged all propositions into 10 final recommendations via discussion and modified Delphi vote. The grade of recommendation according to the Oxford levels of evidence was attributed and the level of agreement was measured on a 10-point numerical rating scale ( $1=$ no agreement, $10=$ full agreement). ${ }^{9}$ Finally, the potential effect of each recommendation in clinical practice was assessed according to three impact statements voted by the rheumatologists.

\section{RESULTS}

A total of 39756 references were identified, of which 250 were systematically reviewed (table 1 ). The 10 multinational key recommendations are listed in table 2 with the corresponding level of evidence and grade of recommendation. The mean level of agreement among the rheumatologists was 8.7 (range 7.4-9.1). The percentage of rheumatologists who indicated they would change their clinical practice according to each recommendation is shown in table 3. Evidence for repeating investigations was not found for any of the questions, therefore all recommendations about this topic were based on expert opinion.

Recommendation 1. All possible causes of arthritis (idiopathic, autoimmune, degenerative, infectious, malignancy, traumatic, metabolic) should be considered in the differential diagnosis. Complete history and thorough physical examination will determine the ranking order of possible differential diagnoses. Investigations should be based on the differential diagnosis of the patient.

Table 1 Results of the systematic literature search for each recommendation topic

\begin{tabular}{lcc}
\hline Recommendation (number and topic) & $\begin{array}{l}\text { Retrieved references by } \\
\text { systematic literature search (n) }\end{array}$ & $\begin{array}{c}\text { Articles included in the } \\
\text { systematic reviews (n) }\end{array}$ \\
\hline 1. Pre-UPIA differential diagnosis and investigations & 540 & 51 \\
2. History and physical examination & 2914 & 37 \\
3. Acute phase reactants & 3699 & 18 \\
4. Autoantibodies & 13217 & 64 \\
5. X-rays & 3585 & 25 \\
6.1. MRI & 2595 & 11 \\
6.2. Ultrasound & 2111 & 2 \\
7. Genetic markers & 3109 & 26 \\
8. Synovial biopsy & 6536 & 4 \\
9. Predictors of persistence (chronicity) & 437 & 7 \\
10. Measures of clinical disease activity & 1013 & 5 \\
Total & 39756 & 250 \\
\hline
\end{tabular}

UPIA, undifferentiated peripheral inflammatory arthritis. 
Table 2 Multinational recommendations on how to investigate and follow-up undifferentiated peripheral inflammatory arthritis

Recommendation (with level of evidence and grade of recommendation)

Agreement mean (SD)

1. All possible causes of arthritis (idiopathic, autoimmune, degenerative, infectious, malignancy, traumatic, metabolic) should be considered in the differential diagnosis. Complete history and thorough physical examination will determine the ranking order of possible differential diagnoses [5, D]. Investigations should be based on the differential diagnosis of the patient [5, D]

2. To establish a specific diagnosis and prognosis following presentation of UPIA, a careful systematic history and physical examination should be performed, with particular attention to age, gender [1a, A], geographical area $[5, D]$, functional status $[1 a, A]$, duration of symptoms/early morning stiffness, number plus pattern of tender/swollen joints [1a, A], axial/entheseal involvement and extra-articular/systemic features [5, D]

3. ESR and CRP should be performed at baseline in the investigation for diagnosis $[2 b, B]$ and prognosis $[2 b, B]$ of UPIA and repeated when clinically relevant $[5, \mathrm{D}]$

4. Testing of RF and/or ACPA should be performed in the evaluation of patients with UPIA, as these factors are predictive of RA diagnosis and prognosis; negative tests do not exclude progression to RA [1a, A]. If a connective tissue disease/systemic inflammatory disorder is suspected, additional autoantibody tests should be considered [5, D]

5. X-rays of affected joints should be performed at baseline $[5, \mathrm{D}]$. X-rays of hands, wrists and feet should be considered in the evaluation of UPIA as the presence of erosions is predictive for the development of RA and persistence of disease [1a, A]. These should be repeated within 1 year [5, D]

6. There is insufficient evidence to recommend the routine use of MRI and US for diagnosis or prognosis in UPIA [5, D]; in UPIA and suspicion of RA, MRI of hands and wrists could be considered for diagnosis [2b, B]

7. There is no genetic test that can be routinely recommended [3b, D], however HLA-B27 testing may be helpful in specific clinical settings [5, D]

8. Routine synovial biopsy is not recommended but can give information for differential diagnosis, especially in patients with persistent monoarthritis $9.0(1.7)$

$[2 b, B]$

9. Predictors of persistent inflammatory arthritis should be documented and include disease duration of $\geq 6$ weeks [1b, A], morning stiffness $>30$ min

$[4, C]$, functional impairment $[4, C]$, involvement of small joints $[4, C]$ and/or knee $[4, C]$, involvement of $\geq 3$ joints $[1 \mathrm{~b}, \mathrm{~B}], \mathrm{ACPA}[4, \mathrm{C}]$ and/or RF positivity

$[4, \mathrm{C}]$ and presence of radiographic erosion $[1 \mathrm{~b}, \mathrm{~B}]$

10. Disease activity should be monitored [5, D], however no specific tool can be recommended [3b, C]

Values in square brackets indicate [level of evidence, grade of recommendation] according to the Oxford Centre for Evidence-based Medicine levels of evidence

Agreement was voted on a scale from 1 to 10 (fully disagree to fully agree) by the 94 rheumatologists attending the 3E Multi-National Closing Meeting. These attendees were members of the 17 scientific committees involved in the 3E Initiative of 2008-2009.

ACPA, anti-citrullinated protein/peptide antibodies; CRP, C reactive protein; ESR, erythrocyte sedimentation rate; RA, rheumatoid arthritis; RF, rheumatoid factor; UPIA, undifferentiated peripheral inflammatory arthritis; US, ultrasound.

Table 3 Percentage of rheumatologists in the $3 E$ Initiative who indicated for each recommendation if it would change their clinical practice

\begin{tabular}{lcc}
\hline Recommendation (number and topic) & $\begin{array}{l}\text { The recommendation will } \\
\text { change my practice (\%) }\end{array}$ & $\begin{array}{l}\text { The recommendation is } \\
\text { already my practice (\%) }\end{array}$ \\
\hline 1. Pre-UPIA differential diagnosis and investigations & 0 & $\begin{array}{l}\text { I don't want to change my } \\
\text { practice for this aspect (\%) }\end{array}$ \\
2. History and physical examination & 0 & 96.5 \\
3. Acute phase reactants & 5.4 & 98.3 \\
4. Autoantibodies & 1.8 & 91.1 \\
5. X-rays & 16.1 & 96.4 \\
6. MRI and ultrasound & 17.9 & 48.2 \\
7. Genetic markers & 1.8 & 64.3 \\
8. Synovial biopsy & 8.9 & 92.9 \\
9. Predictors of persistence (chronicity) & 24.6 & 83.9 \\
10. Measures of clinical disease activity & 12.3 & 66.7 \\
\hline
\end{tabular}

UPIA, undifferentiated peripheral inflammatory arthritis.

As UPIA is an operational diagnosis after excluding welldefined rheumatic diseases, the question about pre-UPIA differential diagnosis and investigations was analysed by looking at the diagnosis that was excluded in cohorts of patients with UPIA and by identifying the inclusion and exclusion criteria of these studies as well as the investigations performed before the UPIA cohort was established. RA was the most frequent diagnosis reported as exclusion criterion ${ }^{10-59}$ and there was no standard baseline investigation undertaken prior to inclusion as UPIA (table 4). ${ }^{41-60}$

Experts agreed that, when facing a new patient presenting with arthritis, every diagnosis needed to be kept in mind as UPIA is an exclusion diagnosis. Although the consensus was that it was impossible to name all possible diagnoses, it was felt useful to mention some major disease categories to make sure that these are considered. Experts also advised that UPIA should be constantly rethought, as patients may develop a disease that can be labelled with a specific diagnosis at any time. Moreover, this recommendation applies only if arthritis persists and not if it is self-limiting. Again, as the investigations will vary according to context and clinical presentation, experts felt that it would not be useful to make a list of recommended minimal investigations.
Recommendation 2. To establish a specific diagnosis and prognosis following presentation of UPIA, a careful systematic history and physical examination should be performed with particular attention to age, gender, geographical area, functional status, duration of symptoms/ early morning stiffness, number plus pattern of tender/swollen joints, axiallentheseal involvement and extra-articular/systemic features.

Although selected observational studies were of good quality, there was large heterogeneity with respect to the type of history and physical examination features described. ${ }^{39} 4042-49$ 61-87 Of the quantified features, advanced age, ${ }^{44} 83$ female gender $^{44}$ and greater morning stiffness ${ }^{43} 44$ were predictive of an eventual diagnosis of RA. A higher number of tender ${ }^{44}$ and swollen joints, ${ }^{43} 4461$ involvement of small joints of hands and feet, ${ }^{44} 83$ involvement of both the upper and lower extremities $^{44}$ and symmetrical involvement ${ }^{43}$ were also associated with progression to RA. Similar features were associated with disease persistence ${ }^{81-87}$ and development of erosions, ${ }^{48} 6378$ while self-reported functional disability (Health Assessment Questionnaire (HAQ) score $)^{67} 76$ and the presence of extraarticular features ${ }^{76}$ were uniquely predictive of future disability, along with advanced age, ${ }^{67} 76$ female gender ${ }^{67}$ and longer symptom duration. ${ }^{67}$ 
Table 4 Diagnosis reported as exclusion criteria and baseline investigations undertaken prior to inclusion as UPIA (ordered by the frequency of reporting in the retrieved literature), both in studies including patients exclusively with UPIA as well as in selected mixed populations that included a well-defined subset of patients with UPIA

\begin{tabular}{|c|c|}
\hline \multicolumn{2}{|l|}{ A. Reported differential diagnosis prior to establishing the operational diagnosis of UPIA } \\
\hline $\begin{array}{l}\text { - Rheumatoid arthritis } \\
\text { - Osteoarthritis } \\
\text { - Spondyloarthritis (reactive arthritis, psoriatic arthritis, ankylosing spondylitis and undifferentiated spondyloarthritis) } \\
\text { - Crystal-related arthritis } \\
\text { - Trauma } \\
\text { - Connective tissue diseases (systemic lupus erythematosus, Sjögren syndrome and myositis) } \\
\text { - Septic arthritis } \\
\text { - Sarcoidosis } \\
\text { - Soft tissue disorders }\end{array}$ & $\begin{array}{l}\text { - Polymyalgia rheumatica } \\
\text { - Lyme disease } \\
\text { - Vasculitis } \\
\text { - Juvenile inflammatory arthritis } \\
\text { - Palindromic rheumatism } \\
\text { - Fibromyalgia } \\
\text { - Endocrinological origin } \\
\text { - Malignancy-related arthritis } \\
\text { - Viral aetiology }\end{array}$ \\
\hline \multicolumn{2}{|l|}{ B. Reported investigations prior to establishing the operational diagnosis of UPIA } \\
\hline $\begin{array}{l}\text { - History } \\
\text { - Tender and swollen joint count } \\
\text { - Rheumatoid factor } \\
\text { - C reactive protein } \\
\text { - Physical examination } \\
\text { - Hands and feet x-rays } \\
\text { - Full blood count } \\
\text { - Antinuclear antibodies } \\
\text { - Erythrocyte sedimentation rate } \\
\text { - Biochemistry (liver function tests, glucose, urate and renal function) } \\
\text { - HLA typing (HLA-B27 and HLA-DR) }\end{array}$ & $\begin{array}{l}\text { - Microbiological assessment } \\
\text { - Anti-citrullinated protein/peptide antibodies } \\
\text { - Radiography of the chest and/or of other affected joints } \\
\text { - Urinalysis } \\
\text { - Thyroid function tests } \\
\text { - C3, C4 } \\
\text { - Immunoglobulins } \\
\text { - Antibodies to extractable nuclear antigens } \\
\text { - Antibodies to double-stranded DNA } \\
\text { - Specific serological assessment }\end{array}$ \\
\hline
\end{tabular}

UPIA, undifferentiated peripheral inflammatory arthritis.

Experts recognised the importance of the abovementioned evidence-based features and, based on their clinical experience, also highlighted the contribution of the patient's geographical area of residence, the presence of axial/entheseal involvement and the presence of extra-articular/systemic features. However, the greater relevance given to features included in the recommendation does not preclude the need to perform a careful systematic history and physical examination in every patient with UPIA.

Recommendation 3. Erythrocyte sedimentation rate (ESR) and $C$ reactive protein $(C R P)$ should be performed at baseline in the investigation for diagnosis and prognosis of UPIA and repeated when clinically relevant.

Elevated erythrocyte sedimentation rate (ESR) showed some diagnostic value for the development of $\mathrm{RA}^{74} 85$ but no prognostic value for persistence (chronicity) or structural damage. $404588 \mathrm{C}$ reactive protein (CRP) appeared to be a poor predictor of persistent arthritis, radiological progression and functional disability. ${ }^{80} 89$ However, there was some evidence for the usefulness of elevated CRP in predicting RA, especially when the CRP levels are higher. ${ }^{48} 88$ In one study, CRP did not have any diagnostic value with regard to spondylarthropathy. ${ }^{39}$ For other acute phase reactants, the evidence on diagnostic or prognostic value was scarce, negative or controversial. $^{32} 42487980$ 90-95

Based on sparse evidence and on personal experience regarding acute phase reactants, experts recommended that only ESR and CRP should be performed at baseline and repeated according to the clinical setting.

Recommendation 4. Testing of rheumatoid factor (RF) and/or ACPA should be performed in the evaluation of patients with UPIA, as these factors are predictive of $R A$ diagnosis and prognosis; negative tests do not exclude progression to $R A$. If a connective tissue disease/systemic inflammatory disorder is suspected, additional autoantibody tests should be considered.

The association of ACPA and rheumatoid factor (RF) $1142-4448$ 5073 96-110 with a diagnosis of RA at follow-up was compelling in the retrieved literature. The absence of ACPA or RF was diagnostically less helpful. The presence of ACPA or RF ${ }^{75}$ 106-109 111-115 also increased the probability of developing persistent synovitis or a worse radiographic outcome..$^{73} 75$ 84-86 116 For anti-keratin antibodies (AKA) and anti-perinuclear factor, the evidence suggests diagnostic usefulness; AKA also appears to have some prognostic value. ${ }^{11}$ 96-99107110114117 For all other markers including a variety of other autoantibodies as well as bone and cartilage biomarkers, the evidence for diagnostic or prognostic value is scarce, negative or controversial. ${ }^{57} 102118-126$ The same applies to disease outcomes different from those already mentioned. ${ }^{59}$ 74768193100116127128

The value of ACPA and RF in UPIA was recognised and, based on clinical experience, experts also advised consideration of additional autoantibody tests if non-RA systemic inflammatory disorders are suspected. The use of the general term ACPA was preferred as the literature describes several tests for detecting antibodies to citrullinated peptides (such as anti-CCP1 and antiCCP2) and newer generation tests are also expected to be used in the future.

Recommendation 5. X-rays of affected joints should be performed at baseline. X-rays of hands, wrists and feet should be considered in the evaluation of UPIA as the presence of erosions is predictive for the development of RA and persistence of disease. These should be repeated within 1 year.

Radiographic erosions ${ }^{43} 49$ and Larsen grade 1 (in a population without erosions at baseline $)^{20}$ increased the probability of developing RA from UPIA. Moreover, when comparing mild versus progressive disease after 1 year follow-up, Sharp/van der Heijde scores at baseline were significantly higher in the progressive disease group. ${ }^{48}$ In another study, ${ }^{44}$ erosions were found to be a predictor of RA in univariate but not in multivariate analysis.

Overall, studies in mixed populations also provided some evidence for the usefulness of x-rays in predicting RA. ${ }^{72} 88$ $92109122 \quad 129-135$ In general, prognosis was worse when radiographic abnormalities at baseline were more severe. ${ }^{75} 91109116$ $133136-140$

Experts recognised the clinical value of hand and feet x-rays in UPIA and, based on clinical experience, also recommended that X-rays of affected joints should be performed at baseline; 
furthermore, experts advised that x-rays should be repeated within 1 year (in case of disease persistence). Moreover, although not voted to be included in the recommendation, some of the experts expressed their opinion that pelvic/sacroiliac joint x-rays should also be considered, particularly in RF- and ACPA-negative patients or if spondyloarthritis is suspected.

There was a slightly lower agreement about this recommendation (table 2, 7.4 agreement), with a larger proportion of experts stating that they did not want to change their practice for this aspect (table 3, 35.7\%). This lower concordance was mainly related to the inclusion of ' $\mathrm{x}$-rays of affected joints at baseline' and about the advice to repeat $\mathrm{x}$-rays 'within 1 year'.

Recommendation 6. There is insufficient evidence to recommend the routine use of magnetic resonance imaging (MRI) and ultrasound (US) for diagnosis or prognosis in UPIA; in UPIA and suspicion of RA, MRI of hands and wrists could be considered for diagnosis.

Bone oedema was found to be an independent predictor of the future development of RA from UPIA, ${ }^{141}$ and the presence of a distinct MRI synovitis and erosion pattern with the involvement of several hand joints but not the first carpometacarpal joint also increased the probability of developing RA. ${ }^{20}$ The absence of the same MRI synovitis pattern decreased the probability of developing RA. ${ }^{20}$ Overall, MRI studies in mixed populations ${ }^{101} 134$ 142-147 provided some evidence for the usefulness of MRI (bone oedema, synovitis and erosions) in predicting RA. Regarding US, two mixed populations revealed US-power Doppler signal and US-gray scale synovitis as potential candidates for future studies in UPIA. 148149

Experts recognised that MRI of the hands and wrists has already been shown to be useful in predicting the development of RA from UPIA, while the value of US in UPIA is still to be determined. However, data are still too scarce to recommend the routine use of any of these imaging tools. This recommendation does not dispute the fact that, compared with physical examination and x-rays, both MRI and US may offer advantages through more sensitive depiction of inflammatory and destructive disease manifestations. The current recommendation pertains only to the diagnostic and prognostic value of these imaging tools in UPIA.

Recommendation 7. There is no genetic test that can be routinely recommended, however HLA-B27 testing may be helpful in specific clinical settings.

There was a great heterogeneity among the genetic markers tested. 394046 50-52 6584127133 150-165 The shared epitope (SE) was the most frequently studied marker. Eight studies 405065 133 153-155 158 tested its diagnostic utility and showed poor results. Only in one study was the positive likelihood ratio for RA relevant, but this result came from the study with the poorest quality and smallest sample size. ${ }^{40}$ In isolation, no other genetic marker was informative of a future diagnosis in patients with UPIA. With regard to prognosis, the SE was weakly associated with a poor prognosis of arthritis in terms of development of erosions, mortality, disability and persistent synovitis. 65127133163164 Other genes were not good predictors of erosions or other less studied outcomes.

The experts acknowledged the current lack of evidence for the practical utility of genetics in UPIA. However, based on their clinical experience, experts chose to highlight that HLAB27 may be helpful in the appropriate clinical setting-namely, when spondyloarthritis is suspected.

Recommendation 8. Routine synovial biopsy is not recommended but can give information for differential diagnosis, especially in patients with persistent monoarthritis.
Studies had significant clinical and statistical heterogeneity. 2223166167 Three broad synovial features of interest were identified in the literature: ACPA staining, immunohistochemistry and vascular patterns. In contrast to serological ACPA testing, ACPA staining was shown not to be highly specific for a diagnosis of RA. ${ }^{167}$ In one study, synovial histopathology seemed to differentiate between RA and non-RA. ${ }^{166}$ The vascular pattern in undifferentiated arthritis was not specific enough to differentiate between spondyloarthritis and RA. ${ }^{22} 23$

The exact role of synovial biopsy in UPIA is yet to be determined and experts felt that it could not be recommended as a routine procedure. However, experts also highlighted the fact that synovial biopsy may give important diagnostic clues, especially in some selected cases (eg, persistent/chronic refractory monarthritis, suspicion of malignancy or suspicion of chronic infection such as tuberculosis).

Recommendation 9. Predictors of persistent inflammatory arthritis should be documented and include disease duration of $\geq 6$ weeks, morning stiffness $>30 \mathrm{~min}$, functional impairment, involvement of small joints and/or knee, involvement of $\geq 3$ joints, ACPA and/or RF positivity and presence of radiographic erosion.

The question about chronicity was investigated by looking at prognostic studies that used multivariate analysis to identify independent predictors of persistence (chronicity). At baseline the following variables were found to be independent predictors of persistent (inflammatory) arthritis: disease duration, ${ }^{75} 82116$ duration of morning stiffness, ${ }^{75} 8586$ change of functional status (measured by HAQ) in the first 3 months, ${ }^{82}$ failure to respond 2 weeks after local treatment with intra-articular corticosteroids, ${ }^{82}$ small joint involvement, ${ }^{168}$ knee involvement, ${ }^{85}$ presence of $\mathrm{RF}^{75}{ }^{85}$ presence and level of ACPA, ${ }^{75} 86168$ functional status (HAQ), ${ }^{169}$ arthritis of at least three joints, ${ }^{75}$ proximal interphalangeal joint involvement, ${ }^{169}$ metatarsophalangeal joint involvement $^{75}$ and radiographic erosion at the hands and feet. ${ }^{75}$ The magnitude of the association in the same predictor was diverse among the studies depending on the patient characteristics (namely, if the population was purely UPIA or not), the study design and the variables used to adjust for in the models.

Recommendation 10. Disease activity should be monitored, however no specific tool can be recommended.

Five studies evaluated the validation of different clinical measures in patients with UPIA. Validation aspects of four questionnaires (WHO Disability Assessment Schedule, ${ }^{170}$ London Handicap Scale, Disease Repercussion Profile and the HAQ ${ }^{171}$ ) and three physical measures (RA Disease Activity Index, ${ }^{172}$ McGill Range of Motion Index ${ }^{173}$ and NOAR Damage Joint Count ${ }^{174}$ ) were partially assessed in these studies but none of the instruments of disease activity was fully validated for its use in UPIA.

Although no instrument of disease activity has been fully validated for its use in UPIA, experts felt that it was important to recommend that there should be a conscious effort to record disease activity.

\section{DISCUSSION}

Ten multinational recommendations on how to investigate and follow-up UPIA in the clinical setting were developed, which are practical, evidence-based and supported by a large panel of international rheumatologists in the $3 \mathrm{E}$ Initiative.

We followed an established group decision method. A representative expert panel of 697 academic and community rheumatologists from 17 countries selected relevant questions that reflect the challenges of approaching a patient with UPIA. They 
openly discussed the evidence from the literature followed by a silent voting process. We used the touch pad methodology with prespecified cut-off levels of agreement to generate the final recommendations. Several rounds of rewording and revoting were sometimes required to reach the specified cut-off for agreement. This process highlights the international dimension of this collaboration and strengthens the current recommendations. ${ }^{1}{ }^{2}$ It ensured that the final recommendations were evidence-driven as well as clinically relevant.

Furthermore, the broad participation increases external validity and enhances future dissemination and implementation into rheumatological practice worldwide. Another main feature of the $3 \mathrm{E}$ Initiative was the promotion of epidemiology and systematic literature research, all participants having been updated on how to appraise published evidence.

There is widespread interest in predictive medicine. Following a strict methodology, we aimed to find all available evidence regarding each question which resulted in a large number of reviewed articles. However, the evidence in truly UPIA populations is scarce, exposing the need to create a research agenda addressing this topic. In particular, future studies should clearly distinguish between individuals with early well-defined rheumatic diseases, individuals with UPIA and individuals with inflammatory joint symptoms but no obvious joint swelling. All these populations can be studied for predictive algorithms and results may be different depending on the study population.

The definition of UPIA is controversial and much of the literature is skewed towards early RA. The difficulty in defining UPIA is underlined by the continuous changing face of different categories of patients, which can be well illustrated by the recent new ACR/EULAR criteria for RA, ${ }^{175}$ as several of the patients we now describe as having UPIA will likely be labelled as having RA. Nevertheless, despite the influence that this changing may have on research and daily practice, the recommendations presented in this article are based on currently available evidence. They may help the clinician in the effective management of patients with UPIA and can be adjusted if future studies or clinical experience reveal new insights.

In summary, multinational recommendations for the investigation and follow-up of patients with undifferentiated arthritis in daily clinical practice were developed, integrating systematic literature review and expert opinion with the aim of promoting evidence-based medicine and ultimately improving patient care.

Acknowledgements The authors thank all members of the $3 E$ scientific committees, all participants of the national meetings, the support from Margaux Orange and the librarians who helped in elaborating the systematic literature searches. CB holds a Canada Research Chair in Knowledge Transfer for Musculoskeletal Care.

Funding This work was supported by Abbott with an unrestricted educational grant.

\section{Competing interests None.}

Provenance and peer review Not commissioned; externally peer reviewed.

Author affiliations ${ }^{1}$ Rheumatology Department, Coimbra University Hospital

Coimbra, Portugal

${ }^{2}$ Rheumatology Department, Leiden University Medical Center, Leiden, The Netherlands

${ }^{3}$ Rheumatology Department, Hospital Universitario de La Princesa, Madrid, Spain

${ }^{4}$ Mount Sinai Hospital, Toronto, Ontario, Canada

${ }^{5}$ Harvard School of Public Health, Boston, Massachusetts, USA

${ }^{6} \mathrm{KH}$ Hietzing, Vienna, Austria

${ }^{7}$ Rheumatology Department, Hospital Universitario Puerta de Hierro Majadahonda, Madrid, Spain

${ }^{8}$ Rheumatology Department, Maastricht University Medical Center, Maastricht, The Netherlands

${ }^{9}$ Rheumatology Department, Atrium Medical Centre Parkstad, Heerlen, The Netherlands
${ }^{10}$ Academic Unit of Musculoskeletal Disease, Leeds Institute of Molecular Medicine,

Leeds University, Leeds, UK

${ }^{11}$ Medical University, Vienna, Austria

${ }^{12}$ Research Unit, Fundación Española de Reumatología, Madrid, Spain

${ }^{13}$ Department of Internal Medicine/Rheumatology, Maastricht University Medical

Center, Care and Public Health Research Institute, Maastricht, The Netherlands

${ }^{14}$ Department of Rheumatology and Clinical Immunology, University Medical Center

Utrecht, Utrecht, The Netherlands

${ }^{15}$ Rheumatology Research Unit, Instituto de Medicina Molecular, Faculdade de Medicina da Universidade de Lisboa, Serviço de Reumatologia e Doenças Ósseas Metabólicas, Hospital de Santa Maria, Lisbon, Portugal

${ }^{16}$ Department of Rheumatology, Karolinska University Hospital and Karolinska Institutet, Stockholm, Sweden

${ }^{17}$ Microbiology Department, Cliniques universitaires Saint-Luc, Université catholique

de Louvain, Brussels, Belgium

${ }^{18}$ Southampton University Hospital, Southampton, UK

${ }^{19}$ Department of Rheumatology, Diakonhjemmet Hospital, Oslo, Norway

${ }^{20}$ State Hospital Stockerau, Center for Rheumatology, Lower Austria, Stockerau,

Austria

${ }^{21}$ Hospital Universitario de Caracas, Ciudad Universitaria, Los Chaguaramos, Caracas, Venezuela

${ }^{22}$ Hospital Universitario La Paz, Department of Rheumatology, Universidad Autónoma, Madrid, Spain

${ }^{23}$ Rheumatology Unit, Centro de Investigación Farmacológica y Biotecnológica, Hospital y Fundación Clínica Médica Sur, México City, México

${ }^{24}$ Cattedra di Reumatologia, IRCCS Policlinico S. Matteo, Università di Pavia, Pavia, Italy

${ }^{25}$ Department of Rheumatology and Clinical Immunology, Justus-Liebig-University

Gießen, Kerckhoff Clinic, Bad Nauheim, Germany

${ }^{26}$ Department of Rheumatology, Copenhagen University Hospitals at Hvidovre and Glostrup, Hvidovre, Denmark

${ }^{27}$ Department of Rheumatology, St James's Hospital, Dublin, Ireland

${ }^{28}$ Hospital de Clínicas de Porto Alegre, Faculdade de Medicina da Universidade Federal do Rio Grande do Sul, Porto Alegre, Rio Grande do Sul, Brazil

${ }^{29}$ Menzies Research Institute, University of Tasmania, Hobart, Australia

${ }^{30}$ Division of Rheumatology, University Health Network, Toronto, Ontario, Canada

${ }^{31}$ Department of Health Policy, Management, and Evaluation, University of Toronto, Toronto, Ontario, Canada

\section{REFERENCES}

1. Sidiropoulos PI, Hatemi G, Song IH, et al. Evidence-based recommendations for the management of ankylosing spondylitis: systematic literature search of the $3 \mathrm{E}$ Initiative in Rheumatology involving a broad panel of experts and practising rheumatologists. Rheumatology (Oxford) 2008;47:355-61.

2. Visser K, Katchamart W, Loza E, et al. Multinational evidence-based recommendations for the use of methotrexate in rheumatic disorders with a focus on rheumatoid arthritis: integrating systematic literature research and expert opinion of a broad international panel of rheumatologists in the 3E Initiative. Ann Rheum Dis 2009;68:1086-93.

3. Sackett DL, Richardson WS, Rosenberg WM, et al. Evidence-based medicine: how to practice and teach EBM. London, UK: Churchill Livingstone, 1997.

4. Arnett FC, Edworthy SM, Bloch DA, et al. The American Rheumatism Association 1987 revised criteria for the classification of rheumatoid arthritis. Arthritis Rheum 1988;31:315-24.

5. Haynes RB, McKibbon KA, Wilczynski NL, et al. Optimal search strategies for retrieving scientifically strong studies of treatment from Medline: analytical survey. BMJ 2005;330:1179.

6. Wilczynski NL, Haynes RB. Developing optimal search strategies for detecting clinically sound prognostic studies in MEDLINE: an analytic survey. BMC Med 2004;2:23

7. Wilczynski NL, Haynes RB. EMBASE search strategies for identifying methodologically sound diagnostic studies for use by clinicians and researchers. BMC Med 2005;3:7.

8. Wilczynski NL, Haynes RB. Optimal search strategies for detecting clinically sound prognostic studies in EMBASE: an analytic survey. J Am Med Inform Assoc 2005; 12:481-5.

9. Roddy E, Zhang W, Doherty M, et al. Evidence-based clinical guidelines: a new system to better determine true strength of recommendation. J Eval Clin Pract 2006;12:347-52.

10. Savolainen E, Kaipiainen-Seppänen 0, Kröger L, et al. Total incidence and distribution of inflammatory joint diseases in a defined population: results from the Kuopio 2000 arthritis survey. J Rheumatol 2003;30:2460-8.

11. Berthelot JM, Maugars $Y$, Castagné $A$, et al. Antiperinuclear factors are present in polyarthritis before ACR criteria for rheumatoid arthritis are fulfilled. Ann Rheum Dis 1997; 56:123-5

12. Blaauw I, Dijkmans B, Bouma P, et al. Rational diagnosis and treatment in unclassified arthritis: how clinical data may guide requests for Lyme serology and antibiotic treatment. Ann Rheum Dis 1993:52:206-10. 
13. O'Hara R, Murphy EP, Whitehead AS, et al. Local expression of the serum amyloid A and formyl peptide receptor-like 1 genes in synovial tissue is associated with matrix metalloproteinase production in patients with inflammatory arthritis. Arthritis Rheum 2004;50:1788-99.

14. Parker JD, Capell HA. An acute arthritis clinic-one year's experience. Br J Rheumatol 1986;25:293-5.

15. Rooney T, Murphy E, Benito M, et al. Synovial tissue interleukin-18 expression and the response to treatment in patients with inflammatory arthritis. Ann Rheum Dis 2004;63:1393-8.

16. Emad Y, Ragab Y, Shaarawy A, et al. Enhanced MRI in early undifferentiated oligoarthritis of the knee joints: improvements already visible after 2 months of DMARDs treatment. Clin Rheumatol 2008;27:1177-82.

17. Appel H, Mertz A, Distler A, et al. The $19 \mathrm{kDa}$ protein of Yersinia enterocolitica 0:3 is recognized on the cellular and humoral level by patients with Yersinia induced reactive arthritis. J Rheumatol 1999;26:1964-71.

18. Inaoui $\mathbf{R}$, Bertin P, Preux PM, et al. Outcome of patients with undifferentiated chronic monoarthritis: retrospective study of 46 cases. Joint Bone Spine 2004;71:209-13.

19. Kaarela K, Tiitinen S, Luukkainen R. Long-term prognosis of monoarthritis. A follow-up study. Scand J Rheumatol 1983;12:374-6.

20. Duer A, Østergaard M, Hørslev-Petersen K, et al. Magnetic resonance imaging and bone scintigraphy in the differential diagnosis of unclassified arthritis. Ann Rheum Dis 2008;67:48-51.

21. Schnarr S, Putschky N, Jendro MC, et al. Chlamydia and Borrelia DNA in synovial fluid of patients with early undifferentiated oligoarthritis: results of a prospective study. Arthritis Rheum 2001;44:2679-85.

22. Baeten D, Kruithof E, De Rycke L, et al. Diagnostic classification of spondylarthropathy and rheumatoid arthritis by synovial histopathology: a prospective study in 154 consecutive patients. Arthritis Rheum 2004;50:2931-41.

23. Cañete JD, Rodríguez JR, Salvador G, et al. Diagnostic usefulness of synovial vascular morphology in chronic arthritis. A systematic survey of 100 cases. Semin Arthritis Rheum 2003;32:378-87.

24. Pazdur J, Ploski R, Bogunia-Kubik K, et al. Can HLA-DRB1 typing have prognostic value in patients with undifferentiated chronic arthritis? Tissue Antigens 1998;51:678-80.

25. Higami K, Hakoda M, Matsuda Y, et al. Lack of association of HLA-DRB1 genotype with radiologic progression in Japanese patients with early rheumatoid arthritis. Arthritis Rheum 1997;40:2241-7.

26. Wilkinson NZ, Kingsley GH, Sieper J, et al. Lack of correlation between the detection of Chlamydia trachomatis DNA in synovial fluid from patients with a range of rheumatic diseases and the presence of an antichlamydial immune response. Arthritis Rheum 1998;41:845-54.

27. Zavala-Cerna MG, Nava A, García-Castañeda E, et al. Serum IgG activity against cyclic citrullinated peptide in patients evaluated for rheumatoid factor correlates with the IgM isotype. Rheumatol Int 2008;28:851-7.

28. Braun J, Laitko S, Treharne J, et al. Chlamydia pneumoniae-a new causative agent of reactive arthritis and undifferentiated oligoarthritis. Ann Rheum Dis 1994;53:100-5.

29. Braun J, Tuszewski M, Ehlers S, et al. Nested polymerase chain reaction strategy simultaneously targeting DNA sequences of multiple bacterial species in inflammatory joint diseases. II. Examination of sacroiliac and knee joint biopsies of patients with spondyloarthropathies and other arthritides. J Rheumatol 1997:24:1101-5

30. Dryll A, Lansaman J, Cazalis P, et al. Light and electron microscopy study of capillaries in normal and inflammatory human synovial membrane. J Clin Pathol 1977; 30:556-62.

31. Fendler C, Laitko $S$, Sörensen $\mathrm{H}$, et al. Frequency of triggering bacteria in patients with reactive arthritis and undifferentiated oligoarthritis and the relative importance of the tests used for diagnosis. Ann Rheum Dis 2001;60:337-43.

32. Hitchon CA, Alex P, Erdile LB, et al. A distinct multicytokine profile is associated with anti-cyclical citrullinated peptide antibodies in patients with early untreated inflammatory arthritis. J Rheumatol 2004;31:2336-46.

33. Jendro MC, Raum E, Schnarr S, et al. Cytokine profile in serum and synovial fluid of arthritis patients with Chlamydia trachomatis infection. Rheumatol Int 2005;25:37-41.

34. Jones VE, Jacoby RK, Cowley PJ, et al. Immune complexes in early arthritis. II. Immune complex constituents are synthesized in the synovium before rheumatoid factors. Clin Exp Immunol 1982;49:31-40.

35. Jones V, Taylor PC, Jacoby RK, et al. Synovial synthesis of rheumatoid factors and immune complex constituents in early arthritis. Ann Rheum Dis 1984:43:235-9.

36. Shine B, Bourne JT, Begum Baig F, et al. C reactive protein and immunoglobulin $\mathrm{G}$ in synovial fluid and serum in joint disease. Ann Rheum Dis 1991;50:32-5.

37. Siala M, Jaulhac B, Gdoura R, et al. Analysis of bacterial DNA in synovial tissue of Tunisian patients with reactive and undifferentiated arthritis by broad-range PCR, cloning and sequencing. Arthritis Res Ther 2008;10:R40.

38. Nissilä M, Isomäki H, Kaarela K, et al. Prognosis of inflammatory joint diseases. A three-year follow-up study. Scand J Rheumatol 1983;12:33-8.

39. Kvien TK, Glennås A, Melby K. Prediction of diagnosis in acute and subacute oligoarthritis of unknown origin. Br J Rheumatol 1996;35:359-63.
40. Morel J, Legouffe MC, Bozonat MC, et al. Outcomes in patients with incipient undifferentiated arthritis. Joint Bone Spine 2000;67:49-53.

41. Verpoort KN, Jol-van der Zijde CM, Papendrecht-van der Voort EA, et al. Isotype distribution of anti-cyclic citrullinated peptide antibodies in undifferentiated arthritis and rheumatoid arthritis reflects an ongoing immune response. Arthritis Rheum 2006;54:3799-808

42. Savolainen E, Kautiainen $\mathrm{H}$, Koivula MK, et al. Change of diagnoses and outcome of patients with early inflammatory joint diseases during a mean 13-month follow-up. Scand J Rheumato/ 2007;36:194-7.

43. van Gaalen FA, Linn-Rasker SP, van Venrooij WJ, et al. Autoantibodies to cyclic citrullinated peptides predict progression to rheumatoid arthritis in patients with undifferentiated arthritis: a prospective cohort study. Arthritis Rheum 2004;50:709-15.

44. van der Helm-van Mil AH, le Cessie $\mathrm{S}$, van Dongen $\mathrm{H}$, et al. A prediction rule for disease outcome in patients with recent-onset undifferentiated arthritis: how to guide individual treatment decisions. Arthritis Rheum 2007:56:433-40.

45. Zeidler H, Werdier D, Klauder A, et al. Undifferentiated arthritis and spondylarthropathy as a challenge for prospective follow-up. Clin Rheumatol 1987;6(Suppl 2):112-20.

46. Hülsemann JL, Zeidler H. Undifferentiated arthritis in an early synovitis out-patient clinic. Clin Exp Rheumatol 1995;13:37-43.

47. Machold KP, Stamm TA, Eberl GJ, et al. Very recent onset arthritis-clinical, laboratory, and radiological findings during the first year of disease. J Rheumatol 2002;29:2278-87.

48. Jansen LM, van Schaardenburg D, van der Horst-Bruinsma IE, et al. One year outcome of undifferentiated polyarthritis. Ann Rheum Dis 2002;61:700-3.

49. van Aken J, van Dongen $\mathrm{H}$, le Cessie $\mathrm{S}$, et al. Comparison of long term outcome of patients with rheumatoid arthritis presenting with undifferentiated arthritis or with rheumatoid arthritis: an observational cohort study. Ann Rheum Dis 2006;65:20-5.

50. van der Helm-van Mil AH, Verpoort KN, Breedveld FC, et al. The HLA-DRB1 shared epitope alleles are primarily a risk factor for anti-cyclic citrullinated peptide antibodies and are not an independent risk factor for development of rheumatoid arthritis. Arthritis Rheum 2006;54:1117-21.

51. Feitsma $\mathbf{A L}$, Toes RE, Begovich $A B$, et al. Risk of progression from undifferentiated arthritis to rheumatoid arthritis: the effect of the PTPN22 1858T-allele in anti-citrullinated peptide antibody positive patients. Rheumatology (Oxford) 2007; 46:1092-5

52. Wesoly J, Hu X, Thabet MM, et al. The 620W allele is the PTPN22 genetic variant conferring susceptibility to RA in a Dutch population. Rheumatology (Oxford) 2007; 46:617-21.

53. Stahl HD, Seidl B, Hubner B, et al. High incidence of parvovirus B19 DNA in synovial tissue of patients with undifferentiated mono- and oligoarthritis. Clin Rheumatol 2000:19:281-6

54. van Dongen $\mathbf{H}$, van Aken J, Lard LR, et al. Efficacy of methotrexate treatment in patients with probable rheumatoid arthritis: a double-blind, randomized, placebocontrolled trial. Arthritis Rheum 2007;56:1424-32.

55. van der Helm-van Mil AH, Verpoort KN, le Cessie S, et al. The HLA-DRB1 shared epitope alleles differ in the interaction with smoking and predisposition to antibodies to cyclic citrullinated peptide. Arthritis Rheum 2007;56:425-32.

56. Verpoort KN, van Gaalen FA, van der Helm-van Mil AH, et al. Association of HLADR3 with anti-cyclic citrullinated peptide antibody-negative rheumatoid arthritis. Arthritis Rheum 2005;52:3058-62.

57. Matsumoto I, Lee DM, Goldbach-Mansky R, et al. Low prevalence of antibodies to glucose-6-phosphate isomerase in patients with rheumatoid arthritis and a spectrum of other chronic autoimmune disorders. Arthritis Rheum 2003;48:944-54.

58. Wilbrink B, van der Heijden IM, Schouls LM, et al. Detection of bacterial DNA in joint samples from patients with undifferentiated arthritis and reactive arthritis, using polymerase chain reaction with universal $16 \mathrm{~S}$ ribosomal RNA primers. Arthritis Rheum 1998;41:535-43.

59. Visser K, Verpoort KN, van Dongen $\mathrm{H}$, et al. Pretreatment serum levels of anti-cyclic citrullinated peptide antibodies are associated with the response to methotrexate in recent-onset arthritis. Ann Rheum Dis 2008;67:1194-5.

60. Saleem B, Mackie S, Quinn M, et al. Does the use of tumour necrosis factor antagonist therapy in poor prognosis, undifferentiated arthritis prevent progression to rheumatoid arthritis? Ann Rheum Dis 2008;67:1178-80.

61. Alarcón GS, Willkens RF, Ward JR, et al. Early undifferentiated connective tissue disease. IV. Musculoskeletal manifestations in a large cohort of patients with undifferentiated connective tissue diseases compared with cohorts of patients with well-established connective tissue diseases: followup analyses in patients with unexplained polyarthritis and patients with rheumatoid arthritis at baseline. Arthritis Rheum 1996;39:403-14.

62. Binard A, Alassane S, Devauchelle-Pensec V, et al. Outcome of early monoarthritis: a followup study. J Rheumatol 2007;34:2351-7.

63. Bukhari $\mathbf{M}$, Lunt $\mathrm{M}$, Barton $\mathrm{A}$, et al. Increasing age at symptom onset is associated with worse radiological damage at presentation in patients with early inflammatory polyarthritis. Ann Rheum Dis 2007:66:389-93.

64. Devlin J, Gough A, Huissoon A, et al. The outcome of knee synovitis in early arthritis provides guidelines for management. Clin Rheumatol 2000;19:82-5. 
65. El-Gabalawy HS, Goldbach-Mansky R, Smith D 2nd, et al. Association of HLA alleles and clinical features in patients with synovitis of recent onset. Arthritis Rheum 1999;42:1696-705.

66. Gerber LH, Furst G, Yarboro C, et al. Number of active joints, not diagnosis, is the primary determinant of function and performance in early synovitis. Clin Exp Rheumatol 2003;21(5 Suppl 31):S65-70.

67. Glennås A, Kvien TK, Andrup 0, et al. Recent onset arthritis in the elderly: a 5 year longitudinal observational study. J Rheumatol 2000;27:101-8.

68. Harrison BJ, Symmons DP, Brennan P, et al. Inflammatory polyarthritis in the community is not a benign disease: predicting functional disability one year after presentation. J Rheumatol 1996;23:1326-31.

69. Hernandez-Avila $\mathbf{M}$, Liang MH, Willett WC, et al. Exogenous sex hormones and the risk of rheumatoid arthritis. Arthritis Rheum 1990;33:947-53.

70. Hernández Avila M, Liang MH, Willett WC, et al. Reproductive factors, smoking and the risk for rheumatoid arthritis. Epidemiology 1990;1:285-91.

71. Jensen $\mathbf{T}$, Klarlund $\mathrm{M}$, Hansen $\mathrm{M}$, et al. Bone loss in unclassified polyarthritis and early rheumatoid arthritis is better detected by digital $\mathrm{x}$ ray radiogrammetry than dual $x$ ray absorptiometry: relationship with disease activity and radiographic outcome. Ann Rheum Dis 2004;63:15-22.

72. Kuriya B, Cheng CK, Chen HM, et al. Validation of a prediction rule for development of rheumatoid arthritis in patients with early undifferentiated arthritis. Ann Rheum Dis 2009;68:1482-5

73. Quinn MA, Green MJ, Marzo-Ortega $\mathrm{H}$, et al. Prognostic factors in a large cohort of patients with early undifferentiated inflammatory arthritis after application of a structured management protocol. Arthritis Rheum 2003;48:3039-45.

74. Schumacher HR, Jr, Habre W, Meador R, et al. Predictive factors in early arthritis: long-term follow-up. Semin Arthritis Rheum 2004;33:264-72.

75. Visser H, le Cessie S, Vos K, et al. How to diagnose rheumatoid arthritis early: a prediction model for persistent (erosive) arthritis. Arthritis Rheum 2002;46:357-65.

76. Wiles NJ, Dunn G, Barrett EM, et al. One year followup variables predict disability 5 years after presentation with inflammatory polyarthritis with greater accuracy than at baseline. J Rheumatol 2000;27:2360-6.

77. Luchikhina EL, Karateev DE, Nasonov EL. Recent onset of inflammatory arthritis in different age groups. Ann Rheum Dis 2007;66(Suppl 2):331.

78. van der Horst-Bruinsma IE, Speyer I, Visser $\mathrm{H}$, et al. Diagnosis and course of earlyonset arthritis: results of a special early arthritis clinic compared to routine patient care. Br J Rheumatol 1998;37:1084-8.

79. Wolfe F, Ross K, Hawley DJ, et al. The prognosis of rheumatoid arthritis and undifferentiated polyarthritis syndrome in the clinic: a study of 1141 patients. J Rheumatol 1993;20:2005-9.

80. Woolf AD, Hall ND, Goulding NJ, et al. Predictors of the long-term outcome of early synovitis: a 5-year follow-up study. Br J Rheumatol 1991;30:251-4.

81. Green M, Marzo-Ortega H, McGonagle D, et al. Persistence of mild, early inflammatory arthritis: the importance of disease duration, rheumatoid factor, and the shared epitope. Arthritis Rheum 1999;42:2184-8.

82. Green M, Marzo-Ortega H, Wakefield RJ, et al. Predictors of outcome in patients with oligoarthritis: results of a protocol of intraarticular corticosteroids to all clinically active joints. Arthritis Rheum 2001;44:1177-83.

83. Mjaavatten MD, Nygaard $\mathrm{H}$, Haugen AJ, et al. Baseline predictors of persistent arthritis, DMARD start and rheumatoid arthritis diagnosis: one year follow-up of 395 patients with very early arthritis. Arthritis Rheum 2008;58:1633.

84. Stockman A, Tait BD, Wolfe R, et al. Clinical, laboratory and genetic markers associated with erosions and remission in patients with early inflammatory arthritis: a prospective cohort study. Rheumatol Int 2006;26:500-9.

85. Tunn EJ, Bacon PA. Differentiating persistent from self-limiting symmetrical synovitis in an early arthritis clinic. Br J Rheumatol 1993;32:97-103.

86. El Miedany $\mathbf{Y}$, Youssef $\mathrm{S}$, Mehanna AN, et al. Development of a scoring system for assessment of outcome of early undifferentiated inflammatory synovitis. Joint Bone Spine 2008;75:155-62.

87. Harrison BJ, Symmons DP, Brennan P, et al. Natural remission in inflammatory polyarthritis: issues of definition and prediction. Br J Rheumatol 1996:35:1096-100.

88. Jensen $\mathbf{T}$, Klarlund $\mathrm{M}$, Hansen $\mathrm{M}$, et al. Connective tissue metabolism in patients with unclassified polyarthritis and early rheumatoid arthritis. Relationship to disease activity, bone mineral density, and radiographic outcome. J Rheumatol 2004;31:1698-708.

89. Mjaavatten MD, Nygaard $\mathrm{H}$, Haugen AJ, et al. Disease characteristics and predictors of persistent arthritis after one year in a very early arthritis clinic in Norway. Ann Rheum Dis 2007;66(Suppl II):332.

90. Jansen LM, van der Horst-Bruinsma IE, van Schaardenburg D, et al. Comparison of the baseline disease activity of early oligo- and polyarthritis in sequential years. Clin Exp Rheumatol 2004;22:447-52.

91. Jansen LM, van der Horst-Bruinsma I, Lems WF, et al. Serological bone markers and joint damage in early polyarthritis. J Rheumatol 2004;31:1491-6.

92. Knudsen LS, Klarlund M, Skjødt H, et al. Biomarkers of inflammation in patients with unclassified polyarthritis and early rheumatoid arthritis. Relationship to disease activity and radiographic outcome. J Rheumatol 2008;35:1277-87.
93. Reneses S, Pestana L, Fernandez-Suarez A, et al. A recent onset inflammatory polyarthritis register in Spain: factors that predict remission. Scand J Rheumatol 2007;36:378-85

94. Hall ND, Blake DR, Bacon PA. Serum sulphydryl levels in early synovitis. J Rheumatol 1982;9:593-6.

95. Alexander GJ, Blake DR, Holman RL, et al. Predictive value of paired plasma and serum viscosity in early rheumatic conditions. BMJ (Clin Res Ed) 1981:282:1198.

96. Saraux A, Berthelot JM, Chalès G, et al. Value of laboratory tests in early prediction of rheumatoid arthritis. Arthritis Rheum 2002;47:155-65.

97. Devauchelle-Pensec V, Saraux A, Youinou P, et al. Antiperinuclear factor and antikeratin/antifilaggrin antibodies for differentiating early rheumatoid arthritis from polymyalgia rheumatica. Joint Bone Spine 2001;68:306-10.

98. Goldbach-Mansky R, Lee J, McCoy A, et al. Rheumatoid arthritis associated autoantibodies in patients with synovitis of recent onset. Arthritis Res 2000;2:236-43.

99. Cordonnier C, Meyer O, Palazzo E, et al. Diagnostic value of anti-RA33 antibody, antikeratin antibody, antiperinuclear factor and antinuclear antibody in early rheumatoid arthritis: comparison with rheumatoid factor. Br J Rheumatol 1996;35:620-4.

100. Verstappen SMM, McCoy MJ, Roberts C, et al. Predictors of poor prognosis in very early inflammatory polyarthritis. Arthritis Rheum 2008;58:S769.

101. Tamai M, Kawakami A, Uetani M, et al. Early prediction of rheumatoid arthritis by serological variables and magnetic resonance imaging of the wrists and finger joints: results from prospective clinical examination. Ann Rheum Dis 2006;65:134-5.

102. van der Helm-van Mil AH, Detert J, le Cessie S, et al. Towards personalized medicine in rheumatology - a prediction rule for the development of rheumatoid arthritis in patients with undifferentiated arthritis. Arthritis Rheum 2008;58:S917.

103. Raza K, Breese M, Nightingale P, et al. Predictive value of antibodies to cyclic citrullinated peptide in patients with very early inflammatory arthritis. J Rheumatol 2005:32:231-8

104. Jansen AL, van der Horst-Bruinsma I, van Schaardenburg D, et al. Rheumatoid factor and antibodies to cyclic citrullinated Peptide differentiate rheumatoid arthritis from undifferentiated polyarthritis in patients with early arthritis. J Rheumatol 2002;29:2074-6.

105. van der Helm-van Mil AH, Detert J, le Cessie S, et al. Validation of a prediction rule for disease outcome in patients with recent-onset undifferentiated arthritis: moving toward individualized treatment decision-making. Arthritis Rheum 2008;58:2241-7.

106. Nell VP, Machold KP, Stamm TA, et al. Autoantibody profiling as early diagnostic and prognostic tool for rheumatoid arthritis. Ann Rheum Dis 2005;64:1731-6.

107. Aho K, Palosuo T, Lukka M, et al. Antifilaggrin antibodies in recent-onset arthritis. Scand J Rheumatol 1999:28:113-16.

108. Schellekens GA, Visser $H$, de Jong BA, et al. The diagnostic properties of rheumatoid arthritis antibodies recognizing a cyclic citrullinated peptide. Arthritis Rheum 2000;43:155-63.

109. Nielen MM, van der Horst AR, van Schaardenburg D, et al. Antibodies to citrullinated human fibrinogen (ACF) have diagnostic and prognostic value in early arthritis. Ann Rheum Dis 2005:64:1199-204.

110. Vittecoq 0, Jouen-Beades F, Krzanowska K, et al. Rheumatoid factors, anti-filaggrin antibodies and low in vitro interleukin-2 and interferon-gamma production are useful immunological markers for early diagnosis of community cases of rheumatoid arthritis. A preliminary study. Joint Bone Spine 2001;68:144-53.

111. Hitchon CA, Wong K, El-Gabalawy HS. Measurement of baseline serum matrix metalloproteinase levels adds minimal prognostic value over routine clinical parameters in the prediction of radiographic erosions in early inflammatory arthritis. Arthritis Rheum 2008;58:S754.

112. Fèvre $\mathbf{C}$, Brazier $\mathrm{M}$, Daragon $\mathrm{A}$, et al. Can we predict structural damage progression at 2 years in very early arthritis? Value of bone and cartilage markers in the conservatively treated community-based inceptive VERA cohort. Ann Rheum Dis 2007;66(Suppl II):324

113. Bukhari M, Thomson W, Naseem H, et al. The performance of anti-cyclic citrullinated peptide antibodies in predicting the severity of radiologic damage in inflammatory polyarthritis: results from the Norfolk Arthritis Register. Arthritis Rheum 2007:56:2929-35.

114. Kurki P, von Essen R, Kaarela K, et al. Antibody to stratum corneum (antikeratin antibody) and antiperinuclear factor: markers for progressive rheumatoid arthritis. Scand J Rheumatol 1997;26:346-9.

115. Teitsson I, Withrington $\mathrm{RH}$, Seifert $\mathrm{MH}$, et al. Prospective study of early rheumatoid arthritis. I. Prognostic value of IgA rheumatoid factor. Ann Rheum Dis 1984:43:673-8.

116. Boire G, Cossette P de Brum-Fernandes AJ, et al. Anti-Sa antibodies and antibodies against cyclic citrullinated peptide are not equivalent as predictors of severe outcomes in patients with recent-onset polyarthritis. Arthritis Res Ther 2005; 7:R592-603.

117. Vittecoq 0, Incaurgarat B, Jouen-Beades F, et al. Autoantibodies recognizing citrullinated rat filaggrin in an ELISA using citrullinated and non-citrullinated recombinant proteins as antigens are highly diagnostic for rheumatoid arthritis. Clin Exp Immunol 2004;135:173-80. 
118. Jouen F, Vittecoq 0, Leguillou F, et al. Diagnostic and prognostic values of anti glucose-6-phosphate isomerase antibodies in community-recruited patients with very early arthritis. Clin Exp Immunol 2004;137:606-11.

119. Vittecoq 0, Salle V, Jouen-Beades F, et al. Autoantibodies to the 27 C-terminal amino acids of calpastatin are detected in a restricted set of connective tissue diseases and may be useful for diagnosis of rheumatoid arthritis in community cases of very early arthritis. Rheumatology (Oxford) 2001;40:1126-34.

120. Goldbach-Mansky R, Lee JM, Hoxworth JM, et al. Active synovial matrix metalloproteinase-2 is associated with radiographic erosions in patients with early synovitis. Arthritis Res 2000;2:145-53.

121. Goldbach-Mansky R, Suson S, Wesley R, et al. Raised granzyme B levels are associated with erosions in patients with early rheumatoid factor positive rheumatoid arthritis. Ann Rheum Dis 2005;64:715-21.

122. Cunnane G, Fitzgerald 0 , Beeton $C$, et al. Early joint erosions and serum levels of matrix metalloproteinase 1, matrix metalloproteinase 3 , and tissue inhibitor of metalloproteinases 1 in rheumatoid arthritis. Arthritis Rheum 2001;44:2263-74.

123. Kudo-Tanaka E, Ohshima S, Ishii M, et al. Autoantibodies to cyclic citrullinated peptide 2 (CCP2) are superior to other potential diagnostic biomarkers for predicting rheumatoid arthritis in early undifferentiated arthritis. Clin Rheumatol 2007;26:1627-33.

124. Boire G, Abrahamowicz M, King LE, et al. Association between serum biomarkers of cartilage turnover and radiographic and symptomatic progression in an early polyarticular inflammatory arthritis cohort. Ann Rheum Dis 2007;66(Suppl II):322.

125. Patel S, Farragher T, Berry J, et al. Association between serum vitamin D metabolite levels and disease activity in patients with early inflammatory polyarthritis. Arthritis Rheum 2007; 56:2143-9.

126. Berthelot JM, Saraux A, Audrain M, et al. Poor predictive value of antinucleosome and antineutrophil cytoplasmic antibodies in a 270 inception cohort of patients with early naked arthritis of less than one year's duration. Ann Rheum Dis 2002;61:760-1.

127. Farragher TM, Goodson NJ, Naseem H, et al. Association of the HLA-DRB1 gene with premature death, particularly from cardiovascular disease, in patients with rheumatoid arthritis and inflammatory polyarthritis. Arthritis Rheum 2008;58:359-69

128. Ortiz AM, González-Álvaro I, García-Vicuña R, et al. Anti-cyclic citrullinated peptide antibodies and high IL-15 serum levels predict better than rheumatoid factor the requirement of intensive treatment in early arthritis patients. Ann Rheum Dis 2007; 66 (Suppl II):593

129. Devauchelle Pensec V, Saraux A, Berthelot JM, et al. Ability of hand radiographs to predict a further diagnosis of rheumatoid arthritis in patients with early arthritis. $J$ Rheumatol 2001;28:2603-7.

130. Devauchelle Pensec V, Saraux A, Berthelot JM, et al. Ability of foot radiographs to predict rheumatoid arthritis in patients with early arthritis. J Rheumatol 2004;31:66-70.

131. Saraux A, Berthelot JM, Chalès G, et al. Ability of the American College of Rheumatology 1987 criteria to predict rheumatoid arthritis in patients with early arthritis and classification of these patients two years later. Arthritis Rheum 2001;44:2485-91.

132. Devauchelle-Pensec V, Berthelot JM, Jousse S, et al. Performance of hand radiographs in predicting the diagnosis in patients with early arthritis. J Rheumatol 2006;33:1511-15.

133. Gough A, Faint J, Salmon M, et al. Genetic typing of patients with inflammatory arthritis at presentation can be used to predict outcome. Arthritis Rheum 1994;37:1166-70.

134. Klarlund M, Ostergaard M, Jensen KE, et al. Magnetic resonance imaging, radiography, and scintigraphy of the finger joints: one year follow up of patients with early arthritis. The TIRA Group. Ann Rheum Dis 2000;59:521-8.

135. Daragon A, Krzanowska K, Vittecoq 0, et al. Prospective X-ray densitometry and ultrasonography study of the hand bones of patients with rheumatoid arthritis of recent onset. Joint Bone Spine 2001;68:34-42.

136. Jansen LM, van Schaardenburg D, van der Horst-Bruinsma I, et al. The predictive value of anti-cyclic citrullinated peptide antibodies in early arthritis. J Rheumatol 2003;30:1691-5.

137. Bukhari M, Lunt M, Harrison BJ, et al. Rheumatoid factor is the major predictor of increasing severity of radiographic erosions in rheumatoid arthritis: results from the Norfolk Arthritis Register Study, a large inception cohort. Arthritis Rheum 2002;46:906-12.

138. Bukhari MA, Wiles NJ, Lunt M, et al. Influence of disease-modifying therapy on radiographic outcome in inflammatory polyarthritis at five years: results from a large observational inception study. Arthritis Rheum 2003;48:46-53.

139. Isomäki H, Martio J, Sarna S, et al. Predicting the outcome of rheumatoid arthritis. A Soviet-Finnish co-operative study. Scand J Rheumatol 1984;13:33-8.

140. Isomäki HA. An epidemiologically based follow-up study of recent arthritis. Incidence, outcome and classification. Clin Rheumatol 1987;6(Suppl 2):53-9.

141. Tamai M, Kawakami A, Uetani M, et al. Anti-cyclic citrullinated peptide antibody and magnetic resonance imaging-detection of bone marrow oedema are most important predictors in classification as well as prognostic evaluation of undifferentiated arthritis. Ann Rheum Dis 2007;66(Suppl II):338.
142. Mori G, Tokunaga D, Takahashi KA, et al. Maximum intensity projection as a tool to diagnose early rheumatoid arthritis. Mod Rheumatol 2008;18:247-51.

143. Narváez J, Sirvent E, Narváez JA, et al. Usefulness of magnetic resonance imaging of the hand versus anticyclic citrullinated peptide antibody testing to confirm the diagnosis of clinically suspected early rheumatoid arthritis in the absence of rheumatoid factor and radiographic erosions. Semin Arthritis Rheum 2008;38:101-9

144. Solau-Gervais $\mathbf{E}$, Legrand JL, Cortet $\mathrm{B}$, et al. Magnetic resonance imaging of the hand for the diagnosis of rheumatoid arthritis in the absence of anti-cyclic citrullinated peptide antibodies: a prospective study. J Rheumatol 2006;33:1760-5

145. Boutry N, Hachulla E, Flipo RM, et al. MR imaging findings in hands in early rheumatoid arthritis: comparison with those in systemic lupus erythematosus and primary Sjögren syndrome. Radiology 2005;236:593-600.

146. Sugimoto H, Takeda A, Hyodoh K. Early-stage rheumatoid arthritis: prospective study of the effectiveness of MR imaging for diagnosis. Radiology 2000;216:569-75.

147. Sugimoto H, Takeda A, Masuyama J, et al. Early-stage rheumatoid arthritis: diagnostic accuracy of MR imaging. Radiology 1996;198:185-92.

148. Freeston J, Wakefield R, Conaghan P, et al. Ultrasound at presentation predicts clinical outcome in very early inflammatory patients. Arthritis Rheum 2007; 56.

149. Scire C, Montecucco C, Epis 0, et al. Residual disease activity assessment by musculoskeletal ultrasounds in early arthritis. Arthritis Rheum 2008;58:S408.

150. Barton A, Bowes J, Eyre S, et al. Investigation of polymorphisms in the PADI4 gene in determining severity of inflammatory polyarthritis. Ann Rheum Dis 2005:64:1311-15

151. Dubost JJ, Demarquilly F, Soubrier M, et al. HLA and self-limiting, unclassified rheumatism. A role for HLA-B35? J Rheumatol 1999;26:2400-3.

152. Saudan-Kister A, Gabay C, Tiercy JM, et al. Adult seronegative arthritis with antinuclear antibodies: a distinct group of patients with a different immunogenetic pattern from seropositive rheumatoid arthritis and a good outcome. Rev Rhum Engl Ed 1996;63:313-20

153. Goëb V, Dieudé P, Daveau R, et al. Contribution of PTPN22 1858T, TNFRII 196R and HLA-shared epitope alleles with rheumatoid factor and anti-citrullinated protein antibodies to very early rheumatoid arthritis diagnosis. Rheumatology (Oxford) 2008;47:1208-12

154. Thomson W, Harrison B, Ollier B, et al. Quantifying the exact role of HLA-DRB1 alleles in susceptibility to inflammatory polyarthritis: results from a large, populationbased study. Arthritis Rheum 1999;42:757-62.

155. Vos K, van der Horst-Bruinsma IE, Hazes JM, et al. Evidence for a protective role of the human leukocyte antigen class II region in early rheumatoid arthritis. Rheumatology (Oxford) 2001:40:133-9.

156. Willis G, Scott DG, Jennings BA, et al. HFE mutations in an inflammatory arthritis population. Rheumatology (Oxford) 2002:41:176-9.

157. Barton A, Lamb R, Symmons D, et al. Macrophage migration inhibitory factor (MIF) gene polymorphism is associated with susceptibility to but not severity of inflammatory polyarthritis. Genes Immun 2003;4:487-91.

158. Jacobsen S, Madsen HO, Klarlund M, et al. The influence of mannose binding lectin polymorphisms on disease outcome in early polyarthritis. TIRA Group. J Rheumatol 2001;28:935-42.

159. Nasrallah NS, Masi AT, Chandler RW, et al. HLA-B27 antigen and rheumatoid factor negative (seronegative) peripheral arthritis. Studies in younger patients with earlydiagnosed arthritis. Am J Med 1977:63:379-86.

160. Naseem H, Thomson W, Silman A, et al. The PTPN22*C1858T functional polymorphism is associated with susceptibility to inflammatory polyarthritis but neither this nor other variants spanning the gene is associated with disease outcome. Ann Rheum Dis 2008;67:251-5.

161. Barton A, Platt H, Salway F, et al. Polymorphisms in the tumour necrosis factor gene are not associated with severity of inflammatory polyarthritis. Ann Rheum Dis 2004;63:280-4

162. Barton A, Platt H, Salway F, et al. Polymorphisms in the mannose binding lectin $(\mathrm{MBL})$ gene are not associated with radiographic erosions in rheumatoid or inflammatory polyarthritis. J Rheumatol 2004;31:442-7.

163. Emery P, Salmon M, Bradley H, et al. Genetically determined factors as predictors of radiological change in patients with early symmetrical arthritis. BMJ 1992; 305:1387-9.

164. Harrison B, Thomson W, Symmons D, et al. The influence of HLA-DRB1 alleles and rheumatoid factor on disease outcome in an inception cohort of patients with early inflammatory arthritis. Arthritis Rheum 1999;42:2174-83.

165. John S, Smith S, Morrison JF, et al. Genetic variation in CCR5 does not predict clinical outcome in inflammatory arthritis. Arthritis Rheum 2003;48:3615-16.

166. Kraan MC, Haringman JJ, Post WJ, et al. Immunohistological analysis of synovial tissue for differential diagnosis in early arthritis. Rheumatology (Oxford) 1999;38:1074-80.

167. Vossenaar ER, Smeets TJ, Kraan MC, et al. The presence of citrullinated proteins is not specific for rheumatoid synovial tissue. Arthritis Rheum 2004;50:3485-94.

168. Mjaavatten MD, Haugen AJ, Helgetveit K, et al. High anti-cyclic citrullinated peptide level is a stronger predictor than low level for persistent joint swelling 
in patients presenting with arthritis of $<=16$ weeks duration. Arthritis Rheum 2008;58:S770

169. Mjaavatten MD, Nygaard $\mathrm{H}$, Helgetveit $\mathrm{K}$, et al. Clinical characteristics of patients presenting with oligoarthritis in a very early arthritis clinic in Norway: predictors of persistent arthritis at six month follow-up. Arthritis Rheum 2007;56:1638.

170. Baron M, Schieir O, Hudson M, et al. The clinimetric properties of the World Health Organization Disability Assessment Schedule II in early inflammatory arthritis. Arthritis Rheum 2008;59:382-90.

171. Harwood RH, Carr AJ, Thompson PW, et al. Handicap in inflammatory arthritis. Br J Rheumatol 1996;35:891-7.
172. Bykerk VP, Mironyuk L, Chen $\mathrm{H}$, et al. Validity of the RADAl in early rheumatoid arthritis. Ann Rheum Dis 2007;66(Suppl II):344.

173. Baron M, Steele R. Development of the McGill Range of Motion Index. Clin Orthop Relat Res 2007;:456:42-50.

174. Bunn DK, Shepstone L, Galpin LM, et al. The NOAR Damaged Joint Count (NOARDJC): a clinical measure for assessing articular damage in patients with early inflammatory polyarthritis including rheumatoid arthritis. Rheumatology (Oxford) 2004;43:1519-25.

175. Aletaha D, Neogi T, Silman A, et al. 2010 Rheumatoid arthritis classification criteria. An American College of Rheumatology/European League Against Rheumatism Collaborative Initiative. Ann Rheum Dis 2010;69:1580-88. 